\title{
The coping strategies during medical education predict style of success in medical career: a 10-year longitudinal study
}

\author{
Małgorzata Tartas ${ }^{1 *}$, Maciej Walkiewicz' ${ }^{1}$ Waldemar Budziński', Mikołaj Majkowicz' ${ }^{1}$ Krzysztof Wójcikiewicz² \\ and Agata Zdun-Ryżewska'
}

\begin{abstract}
Background: The stress associated with the physician's work is generally acknowledged and is related to well-being and life satisfaction. The presented study was designed to extract the role of coping strategies in identifying differentiated styles of success in a medical career during medical education.

Methods: The participants were examined when they applied to medical school and each subsequent academic year. The final study took place four years after graduation. The baseline questionnaire measured coping strategies. The follow-up questionnaire consisted of measures of: quality of life, work stress and burnout, satisfaction with medicine as a career, and professional competency.

Results: Based on coping strategies assessed during admission and preclinical years of medical study, some aspects of success in the participants' future medical career can be predicted. Students who take action and deal directly with a problem, neither accept resignation, nor reduce tension by expressing feelings would most probably resist future burnout. However, despite the fact that they obtain the highest quality of life or earn the highest income they would be, at the same time, the least satisfied with chosen career, as well as being more likely to be characterised by a low level of competence.
\end{abstract}

Conclusions: Assessment of coping strategies at the beginning of medical education could be taken into consideration as an instrument to diagnose a specific trend in physicians' career development.

Keywords: Coping, Longitudinal study, Job satisfaction, Medical students, Medical doctors, Professional success, Burnout, Quality of life

\section{Background}

The stress associated with medical doctor's work is generally acknowledged. Physicians have an increased prevalence of certain mental health problems as compared to the general population [1-4]. During their education they suffer from excessive levels of stress, and distressful occurrences are mostly related to the medical training, rather than to individual psychological qualities [5-8]. The first postgraduate years are particularly stressful. Young doctors may have unrealistic expectations of their future work, and supposable are not enough prepared to

\footnotetext{
* Correspondence: mtartas@gumed.edu.pl

'Faculty of Psychology, Medical University of Gdańsk, Tuwima 15 Street, 80-210 Gdańsk, Poland

Full list of author information is available at the end of the article
}

cope with the associated stress [9-12]. There are limited research data available on the nature of the possible correlation between an undergraduate medical education and the incidence of later professional and psychological problems. It may be that no optimal development of constructive coping strategies, critical thinking, selfreflection, or empathetic reflection takes place at school $[13,14]$. During study the nature of the stressors changes and the medical students may experience a great number of emotional problems and probably need more support $[15,16]$. This causes some coping strategies to be more effective in the different phases of professional development. Students who have begun school and who use avoidant coping strategies, are found to be on risk of evolving mental health problems later [17]. In 
dealing with stressors connected with medical school, students of the preclinical years use more problemsolving and self-blame strategies, and confront coping strategies less [18].

The literature has provided data suggesting that there is no unarguable model that would describe job success in a medical field. The longitudinal study 'Social Diagnosis', which presents information about quality of life of Polish doctors, was an inspiration in developing our model of success in the medical career [19]. The 'Social Diagnosis' research is one of the largest longitudinal psychological studies of quality of life in the population of a specific country. Authors return to the same families every few years $(2000,2003,2005,2007,2009,2011$, 2013,2015 ). In $2015, n=24,324$ (the population of Poland is approximately 38 million). The results of this study also characterise life satisfaction and well-being in Polish physicians, comparing them to other professions [19].

In our research, we devised a specific model based on life satisfaction and well-being, with reference to another model of career success, derived from the literature, to include such complementary factors as job success (performance, happiness at work) and material success [20]. In our model we included work stress and the tendency to burnout as expression of difficulty or defeat in response to career expectations, and as significant measures of success in a medical career [21-24].

In this longitudinal research project (1999-2009), we measured predictors of success in a medical career. The results highlight success as the consequence of personality characteristics rather than as a simple effect of the education process [25]. Coping strategies as an independent variable were followed by academic achievement; sense of coherence, anxiety, depression, value system and need for social approval. The dependent variables group consisted of: satisfaction with medicine as a career, work stress and vulnerability to burnout, quality of life and postgraduate medical competence. The data stated that academic achievement just explained professional competence, while work satisfaction and tendency to burnout were related to job performance, the quality of life was linked to these by psychological profile expressed by: depression, anxiety, sense of coherence, as well as coping strategies. This supported our thinking that success in a medical career is rather the effect of the level of personality structure integration, and not just the simple result of the educational development [25].

In the next stage, in order to improve the practical applicability of the presented data, we identified styles of success in the medical career using the cluster analysis procedure. We managed to indicate three styles, the first of which were those physicians who were 'Committed satisfied with career'. They had the lowest postgraduate medical competence but in the same time they manifest the highest level of work satisfaction. However, they experienced the highest tendency to burnout (and work stress) and were not content with life.

The second style applies to physicians who displayed low competence. They manifest the lowest level of work satisfaction as well as the lowest level of burnout. Their quality of life at this point was the highest. Additionally, they were the most satisfied with life, and they also get the highest financial gratification. Surprisingly, these medical doctors were the least committed to the profession while seeming to derive the most benefit from it. This group we called 'Clever - satisfied with life'.

The third cluster was made up of the most competent physicians, who were, however, dissatisfied with medicine as a career. Although they represented a moderate level of burnout and their quality of life was the lowest. They also achieved the lowest income and they were the most dissatisfied with life, generally. We called them 'Bright - competent' [26, 27] (see Fig. 1, Table 1).

The presented study was designed to extract the role of coping strategies in identifying differentiated styles of success in a medical career during medical education.

\section{Methods}

\section{Participants}

The first stage of the study took place a few days before the admission (June 1999). All candidates who had applied to the Medical University of Gdańsk, Poland received a questionnaires ( $n=365$ of $940,39 \%$ response rate). Only those who passed the admission test were taken into consideration for the purposes of our project $(n=320)$. The procedure was constantly repeated at the end of each academic year (2000-2005). Four years after graduation we cooperated with institutions responsible for postgraduate medical education. The Medical Examination Centre in Poland provided access to the examination results of postgraduates for 268 identified medical doctors. Additionally we cooperated with the Polish Chamber of Physicians in Gdańsk, where we received the addresses of 255 physicians who had participated in the first part of the project. The respondents received a letter sent by the Chamber of Physicians with a request to fill in an electronic questionnaire. The response rate was $n=54$. The mean age of respondents was $29.5 \pm 0.8$ years (July 2009), 69 \% female. The response rates are presented in Table 2:

\section{Measures \\ Independent variables}

The coping strategies at admission and during medical study were measured by Coping Responses Inventory (Moos). The first four subscales assess approach coping responses: 'Logical Analysis' (cognitive attempts to understand a stressor and its consequences), 'Positive Reappraisal' (cognitive attempts to construe and restructure a 


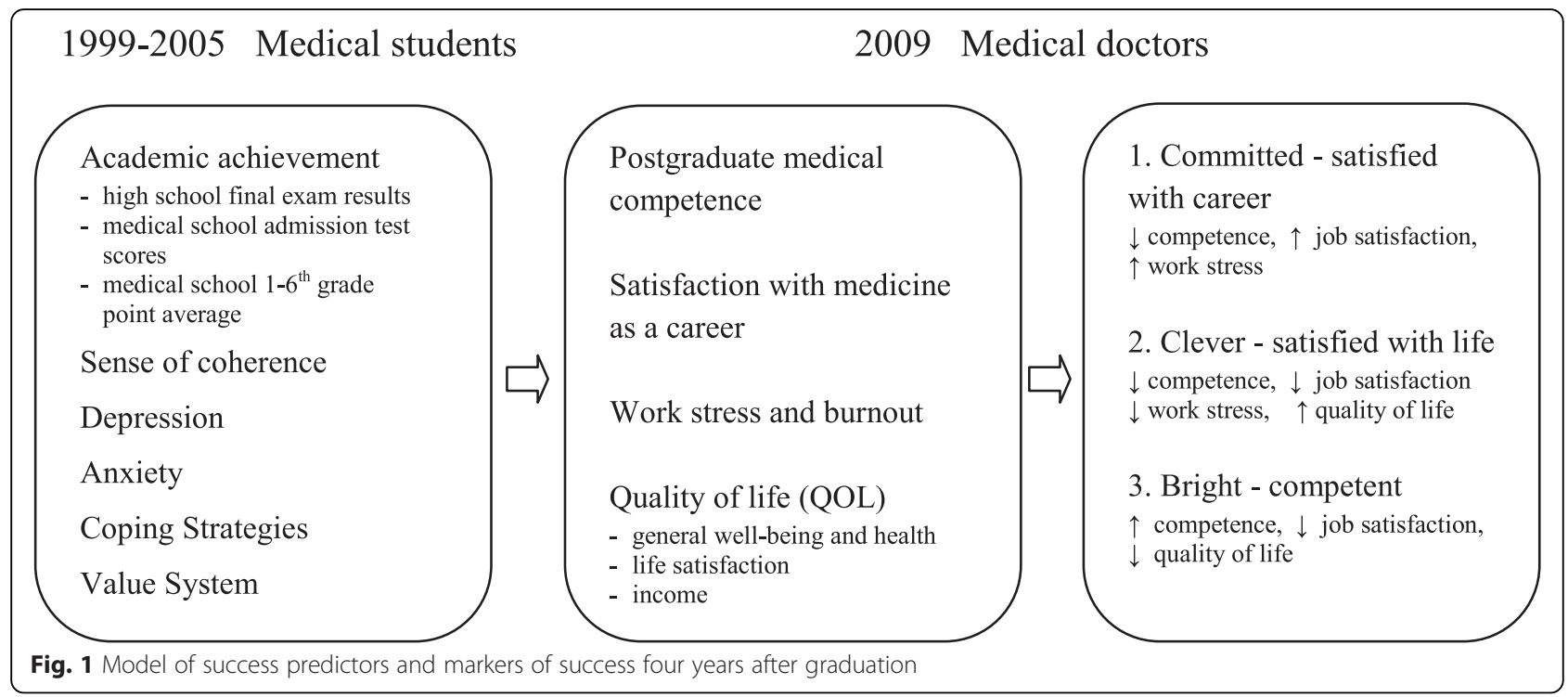

problem in a positive way), 'Guidance and Support Seeking' (behavioural attempts to seek information, guidance, or support) and 'Problem Solving' (behavioural attempts to take action and deal directly with a problem). The second four subscales assess avoidance coping responses: 'Cognitive Avoidance' (cognitive attempts to avoid thinking about a problem), 'Acceptance or Resignation' (cognitive efforts to deal with a problem by accepting it), 'Seeking Alternative Rewards' (behavioural attempts to cope by finding substitute activities or sources of satisfaction), and 'Emotional Discharge' (behavioural efforts to reduce tension by expressing negative feelings) [28-30].

\section{Dependent variables}

We identified three styles of success in a medical career based on significant differences between them in terms of postgraduate medical competence, satisfaction with medicine as a career, work stress and burnout and quality of life [26, 27] (see Fig. 1, Table 1).

The postgraduate medical competence was measured by the examination results in the State Examination for Medical Doctors, supplied by the Medical Examination Centre. In Poland this exam is administered during the postgraduate internship and it is required to gain a license to practice medicine. The results establish whether or not further specialization in medicine will be possible. The exam is organised by the Medical Examination Centre in Łódź each spring and autumn, starts simultaneously in eleven districts and is a multiple-choice test. The second aspect of success - burnout - was measured by the Maslach Burnout Inventory (MBI), which has three sub-scales:

Table 1 Descriptions of the three styles of success in a medical career dimensions: cluster analysis (Bineary Euclidean distance measure and Ward's linkage method)

\begin{tabular}{|c|c|c|c|c|c|c|c|c|}
\hline & $\begin{array}{l}\text { 1. Committed satisfied } \\
\text { with career } \\
n=14\end{array}$ & $\begin{array}{l}\text { 2. Clever satisfied } \\
\text { with life } \\
n=20\end{array}$ & $\begin{array}{l}\text { 3. Bright } \\
\text { unsatisfied } \\
n=16\end{array}$ & & & $\begin{array}{l}\text { Committed vs } \\
\text { Clever }\end{array}$ & $\begin{array}{l}\text { Committed vs } \\
\text { Bright }\end{array}$ & $\begin{array}{l}\text { Clever vs } \\
\text { Bright }\end{array}$ \\
\hline & $M \pm S D$ & $M \pm S D$ & $M \pm S D$ & $F(2 ; 47)$ & $P$ & Tukey's & post- & hoc test \\
\hline $\begin{array}{l}\text { Postgraduate medical } \\
\text { competence }\end{array}$ & $-0.62 \pm 0.61$ & $-0.50 \pm 0.53$ & $1.17 \pm 0.61$ & $48,256^{* * *}$ & $<0.001$ & 0,53 & $<0.001^{* * *}$ & $0,00^{* *}$ \\
\hline $\begin{array}{l}\text { Satisfaction with medicine } \\
\text { as a career }\end{array}$ & $0.95 \pm 0.68$ & $-0.47 \pm 0.47$ & $-0.24 \pm 0.85$ & $20,180^{* * *}$ & $<0.001$ & $<0.001^{* * *}$ & $<0.001^{* * *}$ & 0,31 \\
\hline Work stress and burnout & $0.33 \pm 0.48$ & $-0.27 \pm 0.43$ & $0.07 \pm 0.45$ & $7,365^{* * *}$ & $<0.001$ & $<0.001^{* * *}$ & 0,13 & $0,03^{*}$ \\
\hline $\begin{array}{l}\text { Quality of Life General } \\
\text { well-being }\end{array}$ & $-0.29 \pm 0.81$ & $0.49 \pm 0.55$ & $-0.35 \pm 0.60$ & $9,499^{* * *}$ & $<0.001$ & $<0.001^{* * *}$ & 0,80 & $<0.001^{* * *}$ \\
\hline $\begin{array}{l}\text { Quality of Life } \\
\text { Life satisfaction }\end{array}$ & $-0.60 \pm 0.78$ & $0.76 \pm 0.45$ & $-0.89 \pm 0.86$ & $29,090^{* * *}$ & $<0.001$ & $<0.001^{* * *}$ & 0,26 & $<0.001^{* * *}$ \\
\hline Quality of Life Income & $3.57 \pm 0.51$ & $3.80 \pm 0.41$ & $2.63 \pm 0.89$ & $16,803^{* * *}$ & $<0.001$ & 0,31 & $<0.001^{* * *}$ & $<0.001^{* * *}$ \\
\hline
\end{tabular}

Source: Tartas M, Walkiewicz M, Budziński W, Majkowicz M, Wójcikiewicz K. The sense of coherence and styles of success in the medical career: a longitudinal study. BMC Med Educ. 2014;14:254. doi:10.1186/s12909-014-0254-5

${ }^{*} p<0.05$; ${ }^{* *} p<0.01$; ${ }^{* * *} p<0.001$ 
Table $\mathbf{2}$ The response rates

\begin{tabular}{ll}
\hline 1999 - Admission & $\mathrm{n}=178$ \\
2000 - First year of medical study & $\mathrm{n}=178$ \\
2001 - Second year of medical study & $\mathrm{n}=129$ \\
2002 - Third year of medical study & $\mathrm{n}=127$ \\
2003 - Fourth year of medical study & $\mathrm{n}=121$ \\
2004 - Fifth year of medical study & $\mathrm{n}=58$ \\
2005 - Sixth year of medical study & $\mathrm{n}=138$ \\
2009 - Four year after medical study & $\mathrm{n}=54$ \\
\hline
\end{tabular}

Emotional Exhaustion, Depersonalisation, and Personal Accomplishment [31].

The third parameter of success in medical career satisfaction with medicine as a career - was measured by a self-designed survey based on the Cantril's Scale method, where 1 means "very low" and 10 means "very high" (Cronbach's alpha $=0.80 ; r=0.67$ ).

The quality of life (QoL) - was measured by a questionnaire derived from 'Social Diagnosis' [19].

Quality of life in our research model consisted of:

\section{A) General well-being and health consists of two} questions:

"Thinking about your life over the last two weeks, would you say that it has been: unhappy; not happy; quite happy; very happy".

"Thinking about the whole of your life, would you say that it has been: awful; unhappy; not very successful; neither good nor bad; pretty good; successful; great".

(Cronbach's alpha $=0.74$, Discriminatory power $r=0.40$ ).

B) Life satisfaction. We asked 22 questions about different aspects of human life: social, financial, surroundings and health:

"Please assess these individual aspects of your life, and say how satisfied you are by them: 1 - very satisfied; 2 satisfied; 3 - quite happy; 4 - quite dissatisfied; 5 - dissatisfied; 6 - very dissatisfied; 0 - not applicable".

"Children; the ability to satisfy one's nutritional needs; marriage; your educational level; your state of health; future prospects; relationships with close family members; sexual life; relations with colleagues and superiors; safety in the place of residence; relationships with friends (or group of friends); place of residence; your life achievements; level of available goods and services; housing conditions; manner of spending leisure time; financial situation of the family; current family income; work; moral standards in your environment; the situation in the country" (Cronbach's alpha $=0.83$; Discriminatory power $r=0.25$ ).
C) Size of income.

Statistics

All the statistical methods we used were exploratory in nature, so that the use of subsequent analyses is dependent on the previous outcomes. In the earlier phase of our research, cluster analysis was used to identify styles (clusters) of success. In the present study, ANOVA analysis of variance was used to determine the differences between clusters during studies, cross checked with the coping strategies. In order to reduce this error in the third step, we used discriminant analysis (with the backward method using Ward's estimate). The predictors were variables from ANOVA, and the dependent variables were styles of success (clusters).

\section{Results}

We explored the relation between specificity of coping strategies during medical education and the styles of success in a medical career. In our previous research, we have established three different styles of success [26, 27] (see Fig. 1, Table 1).

We found significant differences in: 'Problem Solving', Approach Coping strategy, 'Acceptance or Resignation' and 'Emotional Discharge' and Avoidant Coping strategy only at the beginning of the education process.

The 'Problem Solving' strategy during admission and the first year of medical studies was the highest in the 'Clever' styles (admission $M=54.30$, first year $M=56.60$ ) and the lowest in the 'Committed' style (admission $\mathrm{M}=$ 47.29 , first year $M=49.00)$. The level of this strategy was significantly higher in 'Clever' than 'Committed'.

In the same moment of education (admission and first year of study), another strategy, 'Acceptance or Resignation' was the lowest in 'Clever' style (admission $M=44.00$, first year $M=44.80$ ), but the highest in 'Bright' group (admission $M=51.38$, first year $M=50.63$ ). However, the 'Clever' have a significantly lower tendency to accept or resign than the 'Bright' only during admission.

The situation changed in the second year, when 'Emotional Discharge' makes a significant difference, as the level of this strategy is the lowest in 'Clever' (admission $M=47.29$, first year $M=49.00$ ).

The 'Emotional Discharge' strategy during first year of medical study was the highest in the 'Bright style (first year $M=65.25$ ) and the lowest in the 'Clever' style (first year $M=57.00)$. This situation changed in the second year when 'Emotional Discharge' makes a significant difference, as the level of this strategy is the highest in 'Committed' style (second year $M=62.57$ ), but still the lowest in 'Clever' style (second year $\mathrm{M}=56.70$ ) (see Table 3). 
Table 3 Means ( \pm standard deviation) for groups representing the three styles of success in the medical career (year 2009), in terms of coping strategies at admission and during medical school (years 1999-2005)

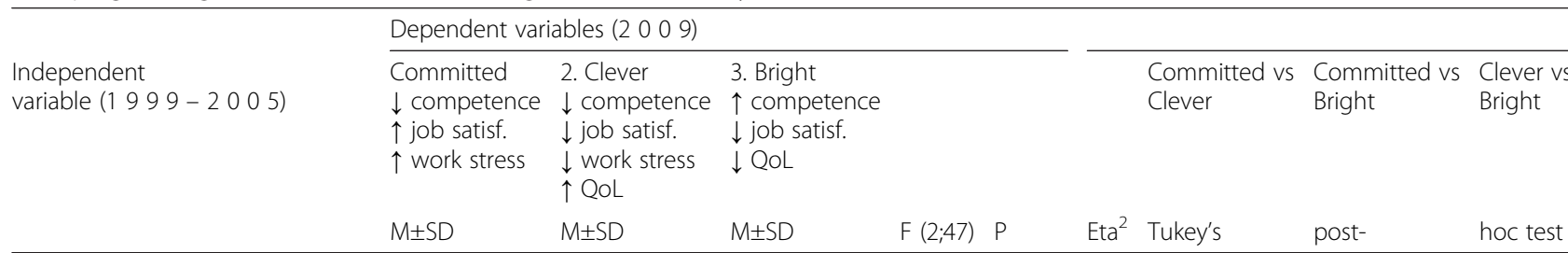

Approach Coping

Logical Analysis (cognitive)

\begin{tabular}{|c|c|c|c|c|c|c|c|c|c|}
\hline 1999 - Admission & $53.43 \pm 2.65$ & $53.60 \pm 5.53$ & $52.88 \pm 5.83$ & 0.097 & 0.907 & & & & \\
\hline 2000 - First year of medical study & $54.14 \pm 3.57$ & $52.20 \pm 7.41$ & $52.38 \pm 5.86$ & 0.481 & 0.621 & & & & \\
\hline 2001 - Second year of medical study & $54.71 \pm 5.20$ & $52.80 \pm 5.67$ & $54.25 \pm 4.37$ & 0.657 & 0.523 & & & & \\
\hline 2002 - Third year of medical study & $54.71 \pm 5.20$ & $52.30 \pm 6.62$ & $54.25 \pm 4.37$ & 0.926 & 0.403 & & & & \\
\hline 2003 - Fourth year of medical study & $52.86 \pm 2.85$ & $52.60 \pm 6.67$ & $53.63 \pm 4.29$ & 0.187 & 0.830 & & & & \\
\hline 2004 - Fifth year of medical study & $54.71 \pm 6.02$ & $52.30 \pm 6.76$ & $54.38 \pm 3.69$ & 0.925 & 0.404 & & & & \\
\hline 2005 - Sixth year of medical study & $55.71 \pm 6.22$ & $52.30 \pm 6.76$ & $54.38 \pm 3.69$ & 1.505 & 0.232 & & & & \\
\hline \multicolumn{10}{|l|}{ Positive Reappraisal (cognitive) } \\
\hline 1999 - Admission & $51.14 \pm 6.46$ & $51.20 \pm 5.58$ & $48.00 \pm 8.50$ & 1.164 & 0.321 & & & & \\
\hline 2000 - First year of medical study & $49.29 \pm 6.97$ & $52.20 \pm 6.88$ & $47.75 \pm 8.47$ & 1.668 & 0.200 & & & & \\
\hline 2001 - Second year of medical study & $52.00 \pm 6.97$ & $51.30 \pm 7.06$ & $50.88 \pm 6.96$ & 0.098 & 0.907 & & & & \\
\hline 2002 - Third year of medical study & $52.00 \pm 6.97$ & $51.30 \pm 6.79$ & $50.88 \pm 6.96$ & 0.101 & 0.904 & & & & \\
\hline 2003 - Fourth year of medical study & $50.57 \pm 6.25$ & $52.20 \pm 6.91$ & $51.25 \pm 6.88$ & 0.251 & 0.779 & & & & \\
\hline 2004 - Fifth year of medical study & $53.00 \pm 5.71$ & $50.40 \pm 6.60$ & $51.25 \pm 6.88$ & 0.673 & 0.515 & & & & \\
\hline 2005 - Sixth year of medical study & $52.43 \pm 5.63$ & $50.40 \pm 6.60$ & $51.25 \pm 6.88$ & 0.408 & 0.667 & & & & \\
\hline \multicolumn{10}{|c|}{ Guidance and Support Seeking (behavioral) } \\
\hline 1999 - Admission & $54.71 \pm 10.01$ & $54.30 \pm 8.75$ & $54.63 \pm 8.50$ & 0.010 & 0.990 & & & & \\
\hline 2000 - First year of medical study & $54.71 \pm 10.75$ & $55.60 \pm 6.90$ & $56.50 \pm 7.83$ & 0.169 & 0.845 & & & & \\
\hline 2001 - Second year of medical study & $53.14 \pm 9.74$ & $55.60 \pm 8.84$ & $56.25 \pm 6.87$ & 0.547 & 0.582 & & & & \\
\hline 2002 - Third year of medical study & $53.14 \pm 9.74$ & $57.90 \pm 6.45$ & $56.25 \pm 6.87$ & 1.613 & 0.210 & & & & \\
\hline 2003 - Fourth year of medical study & $52.86 \pm 9.82$ & $58.40 \pm 5.70$ & $55.00 \pm 5.24$ & 2.745 & 0.075 & 0,12 & 0,07 & 0,68 & 0,32 \\
\hline 2004 - Fifth year of medical study & $56.00 \pm 10.26$ & $56.50 \pm 6.51$ & $55.38 \pm 5.26$ & 0.102 & 0.903 & & & & \\
\hline 2005 - Sixth year of medical study & $57.14 \pm 11.00$ & $56.50 \pm 6.51$ & $56.00 \pm 5.96$ & 0.079 & 0.924 & & & & \\
\hline \multicolumn{10}{|l|}{ Problem Solving (behavioral) } \\
\hline 1999 - Admission & $47.29 \pm 6.92$ & $54.30 \pm 8.74$ & $53.25 \pm 4.43$ & 4.382 & $0.018^{*}$ & 0,19 & $0,02^{*}$ & 0,07 & 0,90 \\
\hline 2000 - First year of medical study & $49.00 \pm 8.06$ & $56.60 \pm 7.88$ & $55.13 \pm 5.25$ & 4.871 & $0.012^{*}$ & 0,21 & $0,01^{*}$ & 0,06 & 0,82 \\
\hline 2001 - Second year of medical study & $51.86 \pm 7.22$ & $54.60 \pm 7.14$ & $52.50 \pm 5.24$ & 0.824 & 0.445 & & & & \\
\hline 2002 - Third year of medical study & $51.86 \pm 7.22$ & $53.80 \pm 7.92$ & $52.50 \pm 5.24$ & 0.348 & 0.708 & & & & \\
\hline 2003 - Fourth year of medical study & $50.71 \pm 6.85$ & $54.80 \pm 6.96$ & $52.13 \pm 5.15$ & 1.806 & 0.175 & & & & \\
\hline 04 - Fifth year of medical study & $54.00 \pm 6.61$ & $53.80 \pm 7.24$ & $53.00 \pm 5.22$ & 0.105 & 0.901 & & & & \\
\hline 2005 - Sixth year of medical study & $54.43 \pm 6.56$ & $53.80 \pm 7.24$ & $53.38 \pm 5.61$ & 0.097 & 0.908 & & & & \\
\hline \multicolumn{10}{|l|}{ Avoidant Coping } \\
\hline \multicolumn{10}{|l|}{ Cognitive Avoidance (cognitive) } \\
\hline 99 - Admission & $51.71 \pm 10.69$ & $50.20 \pm 6.32$ & $48.38 \pm 6.34$ & 0.694 & 0.505 & & & & \\
\hline 00 - First year of medical study & $51.29 \pm 10.88$ & $50.50 \pm 5.11$ & $50.75 \pm 8.88$ & 0.038 & 0.963 & & & & \\
\hline 01 - Second year of medical study & $47.29 \pm 9.81$ & $50.80 \pm 5.23$ & $50.63 \pm 8.23$ & 1.006 & 0.373 & & & & \\
\hline 2 - Third year of medical study & $47.29 \pm 9.81$ & $52.20 \pm 5.63$ & $50.63 \pm 8.23$ & 1.647 & 0.204 & & & & \\
\hline
\end{tabular}


Table 3 Means ( \pm standard deviation) for groups representing the three styles of success in the medical career (year 2009), in terms of coping strategies at admission and during medical school (years 1999-2005) (Continued)

\begin{tabular}{|c|c|c|c|c|c|c|c|c|c|}
\hline 2003 - Fourth year of medical study & $48.57 \pm 8.48$ & $50.90 \pm 5.96$ & $52.38 \pm 6.87$ & 1.107 & 0.339 & & & & \\
\hline 2004 - Fifth year of medical study & $46.86 \pm 7.49$ & $49.80 \pm 6.44$ & $51.50 \pm 7.38$ & 1.648 & 0.203 & & & & \\
\hline 2005 - Sixth year of medical study & $45.86 \pm 8.03$ & $49.80 \pm 6.44$ & $50.88 \pm 8.04$ & 1.877 & 0.164 & & & & \\
\hline \multicolumn{10}{|l|}{ Acceptance or Resignation (cognitive) } \\
\hline 1999 - Admission & $48.86 \pm 4.59$ & $44.00 \pm 5.29$ & $51.38 \pm 7.90$ & 6.863 & $0.002^{* *}$ & 0.29 & 0.07 & 0.50 & $0.00^{*}$ \\
\hline 2000 - First year of medical study & $49.57 \pm 5.37$ & $44.80 \pm 5.44$ & $50.63 \pm 8.67$ & 3.976 & $0.025^{*}$ & 0.17 & 0.11 & 0.90 & 0.03 \\
\hline 2001 - Second year of medical study & $43.57 \pm 5.43$ & $44.00 \pm 4.18$ & $47.63 \pm 5.56$ & 3.164 & 0.051 & 0.13 & 0.97 & 0.08 & 0.09 \\
\hline 2002 - Third year of medical study & $43.57 \pm 5.43$ & $44.50 \pm 4.80$ & $47.63 \pm 5.56$ & 2.579 & 0.087 & 0.11 & 0.87 & 0.10 & 0.19 \\
\hline 2003 - Fourth year of medical study & $45.29 \pm 7.25$ & $44.50 \pm 5.11$ & $48.63 \pm 4.62$ & 2.544 & 0.089 & 0.11 & 0.92 & 0.25 & 0.09 \\
\hline 2004 - Fifth year of medical study & $45.14 \pm 3.11$ & $44.50 \pm 6.84$ & $48.00 \pm 5.14$ & 1.954 & 0.153 & & & & \\
\hline 2005 - Sixth year of medical study & $43.86 \pm 5.27$ & $44.50 \pm 6.84$ & $48.63 \pm 4.62$ & 3.188 & 0.050 & 0.14 & 0.95 & 0.07 & 0.10 \\
\hline \multicolumn{10}{|c|}{ Seeking Alternative Rewards (behavioral) } \\
\hline 1999 - Admission & $54.57 \pm 5.29$ & $56.50 \pm 6.76$ & $54.38 \pm 7.15$ & 0.586 & 0.560 & & & & \\
\hline 2000 - First year of medical study & $55.86 \pm 5.07$ & $58.40 \pm 6.73$ & $56.00 \pm 6.85$ & 0.906 & 0.411 & & & & \\
\hline 2001 - Second year of medical study & $53.29 \pm 5.37$ & $55.90 \pm 5.55$ & $52.50 \pm 6.87$ & 1.620 & 0.209 & & & & \\
\hline 2002 - Third year of medical study & $53.29 \pm 5.37$ & $56.30 \pm 4.57$ & $52.50 \pm 6.87$ & 2.321 & 0.109 & & & & \\
\hline 2003 - Fourth year of medical study & $52.86 \pm 5.36$ & $56.30 \pm 3.37$ & $54.25 \pm 7.24$ & 1.740 & 0.187 & & & & \\
\hline 2004 - Fifth year of medical study & $54.86 \pm 5.13$ & $56.10 \pm 6.23$ & $52.38 \pm 7.10$ & 1.601 & 0.212 & & & & \\
\hline 2005 - Sixth year of medical study & $55.14 \pm 5.96$ & $56.10 \pm 6.23$ & $53.00 \pm 7.36$ & 1.019 & 0.369 & & & & \\
\hline \multicolumn{10}{|l|}{ Emotional Discharge (behavioral) } \\
\hline 1999 - Admission & $61.43 \pm 11.66$ & $57.00 \pm 6.16$ & $65.25 \pm 6.88$ & 4.488 & $0.016^{*}$ & 0.19 & 0.28 & 0.42 & $0.01^{*}$ \\
\hline 2000 - First year of medical study & $61.86 \pm 11.29$ & $58.20 \pm 4.40$ & $62.25 \pm 6.34$ & 1.615 & 0.210 & & & & \\
\hline 2001 - Second year of medical study & $62.57 \pm 9.91$ & $56.70 \pm 5.75$ & $61.50 \pm 5.59$ & 3.425 & $0.041^{*}$ & 0.15 & 0.06 & 0.91 & 0.12 \\
\hline 2002 - Third year of medical study & $62.57 \pm 9.91$ & $57.90 \pm 6.75$ & $61.50 \pm 5.59$ & 1.894 & 0.162 & & & & \\
\hline 2003 - Fourth year of medical study & $62.29 \pm 11.47$ & $57.30 \pm 6.52$ & $60.75 \pm 5.31$ & 1.805 & 0.176 & & & & \\
\hline 2004 - Fifth year of medical study & $62.29 \pm 12.10$ & $59.40 \pm 4.52$ & $61.88 \pm 5.35$ & 0.748 & 0.479 & & & & \\
\hline 2005 - Sixth year of medical study & $60.14 \pm 14.64$ & $59.40 \pm 4.52$ & $61.50 \pm 5.59$ & 0.255 & 0.776 & & & & \\
\hline
\end{tabular}

${ }^{*} p<0.05 ;{ }^{* *} p<0.01 ;{ }^{* * *} p<0.001$

\section{Discussion}

According to the presented data, we would underline that admission and the beginning of medical studies (first and second year) constitutes the moment coping strategies are significant factors in specific predictions of the future style of success in a medical career.

Our findings widely describe the main specific ways of coping in medical students, who, as a physicians, would not be in the risk group of burnout. The group was called 'Clever - satisfied with life'. During medical studies, they use behavioural attempts to take action and deal directly with problems, however, they do not use cognitive efforts to accept or resign. They do not use behavioural efforts to reduce tension by expressing negative feelings. Later, as physician, they are resistant of burnout, have the highest quality of life and income, a low level of postgraduate competence, and the least satisfaction with their chosen career. Presumably, they are not overly engaged, and so have other life priorities and values. This is why they are not in the risk group of burnout. Conversely, in terms of coping, students, who, as physicians, are the most competent, have difficulties with governing their lives. They were called the 'Bright competent'. These students cope with stress by using cognitive efforts, in this case dealing with problems by accepting them. They also introduce behavioural efforts to reduce tension by directly expressing negative feelings. As physicians, they are likely to give up, e.g. towards the limitations of the curative process, but could bring up difficulties in the relationships because they are more likely to express emotions than other groups. The last style called 'Committed - satisfied with career', the most involved in their work, have the highest level of work stress as well as vulnerability to burnout. During studies they have the lowest level of problem solving competency. 
We are most easily able to predict belonging to the 'Clever' group, according to specific coping at admission and the first and second year of study, while differentiating between the other two groups, 'Bright' and 'Committed', is not as precise. 'Bright' could be differentiated in the same moment only based on two strategies and 'Committed', due to their limitation, which is a deficit of specific strategy at the admission and the first year.

Assessment of coping is not a perfect way to diagnose a specific tendency in medical career development. However, according to the presented data it could provide a background to job counselling, as well as a personal development process for medical students, starting from their admission. This could be identified as a strength of the presented study. Compared to other studies, our findings introduce long-term monitoring of the practical application of the coping concept in a medical career.

Although our study presents a range of serious limitations, e.g. the evidence does not propose an consistent clarification of the styles of success for the whole of the physician representation, it may add a valuable perspective to the understanding of the development of a medical career. Attempts to assess the link between styles of success and the coping process in medical training in the future, should be based on a larger research population, as it would be challenging to consider coping strategies in drop-outs from medical career.

\section{Conclusions}

Coping strategies are of great importance to identify specific group of medical students and their way of career development. They are problem oriented, not very likely to resign neither nor to express negative feelings. What needs highlighting they are satisfied with their lives.

\section{Abbreviations}

MBI, Maslach Burnout Inventory; QoL, quality of life

\section{Acknowledgements}

We are very grateful to our respondents for taking part in our research. We would also like to thank Prof. Mariusz Klencki, MD, PhD, of the Medical Examination Centre, Poland, for permission to analyze the examination results of postgraduates; Zdzisława Cieplińska of the Department of Psychology at the Medical University of Gdańsk, Poland for organizational help and Karol Karasiewicz, PhD, the Department of Statistics and Psychometrics, Institute of Psychology, University of Gdańsk, Poland for statistical advice.

\section{Funding}

This longitudinal research program was supported by grants ST-50\#19982006 (manager - Waldemar Budziński, PhD) and W-139\#2009-2010 (manager - Maciej Walkiewicz, PhD), funded by the Medical University of Gdańsk,

Poland and the Polish Ministry of Science and Higher Education.

\section{Availability of data and materials}

Datasets supporting the conclusions of this article are included within the article. Additional data e.g. the participant survey data are not publicly available for participant privacy protection. Raw data is held by the authors.

\section{Authors' contributions}

MT and WB designed and acquisitioned the first part of the research (1998-2006). MW and MM designed and acquisitioned the second part of the research (2009-2010), KW helped with acquisitioned data. MT and MW analysed, interpreting the data and finally drafted the article. AZR had been involved in drafting the manuscript. We assess our intellectual contributions as: MT $40 \%$, MW $40 \%$, WB $5 \%$, MM $5 \%$, KW $5 \%$, and AZR $5 \%$. All authors read and approved the final manuscript.

\section{Authors' information}

MAtGORZATA TARTAS, PhD, is a clinical psychologist, psychoanalytical psychotherapist and university teacher. Her main research interests are in the area of mental disorders and psychoanalysis.

MACIEJ WALKIEWICZ, PhD, is a clinical psychologist and university teacher. His primary research interest is in assessing the competence and performance of medical students and practicing doctors, and psychotherapy.

WALDEMAR BUDZINSKI, PhD, is a clinical psychologist and university teacher. His primary research interest is clinical child psychology.

MIKOŁAJ MAJKOWICZ, PhD, is a clinical psychologist and professor in the Department of Psychology at the Medical University of Gdańsk, Poland. His main interests are in the area of psychometric methods especially in quality of life research.

KRZYSZTOF WÓJCIKIEWICZ, MD, is a medical doctor, Authority in the Polish Chamber of Physicians in Gdańsk and Medical Director in the Copernicus Hospital in Gdańsk, Poland.

AGATA ZDUN-RYŻEWSKA, PhD, is a psychologist and university teacher. Her primary research interest is psychooncology.

\section{Competing interests}

The authors declare that they have no competing interests.

\section{Consent for publication}

Not applicable.

\section{Ethics approval and consent to participate}

The study was specifically reviewed and approved by the the Bioethics Committee of the Medical University of Gdańsk, Poland [NKEBN/329-2008/ 2009]. The research did not involve any handling of sensitive personal data or clinical procedures and, therefore no other special consent was required.

\section{Author details}

${ }^{1}$ Faculty of Psychology, Medical University of Gdańsk, Tuwima 15 Street, 80-210 Gdańsk, Poland. ${ }^{2}$ Polish Chamber of Physicians in Gdansk, Śniadeckich 33 Street, 80-204 Gdańsk, Poland.

Received: 31 October 2015 Accepted: 8 July 2016

Published online: 22 July 2016

References

1. Shanafelt TD, Boone S, Tan L, Dyrbye LN, Sotile W, Satele D, et al. Burnout and satisfaction with work-life balance among US physicians relative to the general US population. Arch Intern Med. 2012;172(18):1377-85.

2. Roessler W. Stress, burnout, and job dissatisfaction in mental health workers. Eur Arch Psychiatry Clin Neurosci. 2012;262(2):65-9. doi:10.1007/s00406-0120353-4.

3. Meerten M, Rost F, Bland J, Garelick Al. Self-referrals to a doctor's mental health service over 10 years. Occup Med (Lond). 2014;64(3):172-6. doi:10. 1093/occmed/kqt177.

4. Chou LP, Li CY, Hu SC. Job stress and burnout in hospital employees: comparisons of different medical professions in a regional hospital in Taiwan. BMJ Open. 2014;4(2):e004185. doi:10.1136/bmjopen-2013-004185.

5. Adams J. Straining to describe and tackle stress in medical students. Med Educ. 2004:38(5):463-4.

6. Moffat KJ, McConnachie A, Ross S, Morrison JM. First year medical student stress and coping in a problem-based learning medical curriculum. Med Educ. 2004:38(5):482-91.

7. Ripp J, Fallar R, Babyarsky M, Rand D, Reich L, Korenstein D. Prevalence of resident burnout at the start of training. Teach Learn Med. 2010;22(3):172-5. doi:10.1080/10401334.2010.488194.

8. Henning M, Krägeloh C, Hawken S, Zhao Y, Doherty I. The quality of life of medical students studying in New Zealand: a comparison with nonmedical 
students and a general population reference group. Teach Learn Med. 2012; 24(4):334-40. doi:10.1080/10401334.2012.715261.

9. Coles CR. Learning to cope: stress and medical career development in the United Kingdom. Med Educ. 1994;28:18-25.

10. Buddeberg-Fischer B, Stamm M, Buddeberg C, Klaghofer R. Chronic stress experience in young physicians: impact of person- and workplace-related factors. Int Arch Occup Environ Health. 2010;83(4):373-9. doi:10.1007/ s00420-009-0467-9.

11. Ripp J, Babyatsky M, Fallar R, Bazari H, Bellini L, Kapadia C, et al. The incidence and predictors of job burnout in first-year internal medicine residents: a five-institution study. Acad Med. 2011;86(10):1304-10. doi:10. 1097/ACM.0b013e31822c1236.

12. Dyrbye LN, West CP, Satele D, Boone S, Tan L, Sloan J, Shanafelt TD. Burnout among u. s. medical students, residents, and early career physicians relative to the general U.S. population. Acad Med. 2014;89(3):443-51. doi:10. 1097/ACM.0000000000000134.

13. Lowry S. What's wrong with medical education in Britain. BMJ. 1992;305: 1277-80.

14. Vitaliano PP, Maiuro RD, Russo J, Mitchell ES. Medical student distress. A longitudinal study. J Nerv Ment Dis. 1989;177(2):70-6.

15. Wolf TM. Stress, coping and health: enhancing well-being during medical school. Med Educ. 1994:28:8-17.

16. Deary IJ. Need medical education be stressful? Med Educ. 1994;28:55-7.

17. Stewart SM, Betson C, Lam TH, Marshall IB, Lee PW, Wong CM. Predicting stress in first year medical students: a longitudinal study. Med Educ. 1997; 31(3):163-8.

18. Stern M, Norman S, Komm C. Medical students' differential use of coping strategies as a function of stressor type, year of training, and gender. Behav Med. 1993;18(4):173-80.

19. Czapinski J. Social diagnosis 2015 objective and subjective quality of life in Poland - full report. Warszawa: Rada Monitoringu Społecznego. [Polish]

20. Gattiker UE, Larwood L. Subjective career success: a study of managers and support personnel. J Bus Psychol. 1986;1(2):78-94.

21. Edwards JA, Guppy A, Cockerton T. A longitudinal study exploring the relationships between occupational stressors, non-work stressors, and work performance. Work Stress. 2007;21(2):99-116. doi:10.1080/02678370701466900.

22. Ferguson E, James D, Madeley L. Factors associated with success in medical school: systematic review of the literature. BMJ. 2002;324(7343):952-7. doi: 10.1136/bmj.324.7343.952.

23. Schaufeli WB, Bakker AB, Van der Heijden F, Prins JT. Workaholism, burnout and well-being among junior doctors: the mediating role of role conflict. Work Stress. 2009;23(2):155-72. doi:10.1080/02678370902834021.

24. Woloschuk W, McLaughlin K, Wright B. Is undergraduate performance predictive of postgraduate performance? Teach Learn Med. 2010;22(3):202-4. doi:10.1080/10401334.2010.488205

25. Tartas M, Walkiewicz M, Majkowicz M, Budzinski W. Psychological factors determining success in a medical career: a 10-year longitudinal study. Med Teach. 2011:33(3):e163-72. doi:10.3109/0142159X.2011.544795.

26. Walkiewicz M, Tartas M, Budzinski W, Majkowicz M. Academic achievement, depression and anxiety during Med Educ predict the styles of success in a medical career: a 10-year longitudinal study. Med Teach. 2012;34(9):e611-9.

27. Tartas M, Walkiewicz M, Budziński W, Majkowicz M, Wójcikiewicz K. The senseof coherence and styles of success in the medical career: a longitudinal study. BMC Med Educ. 2014;14:254.

28. Holahan C, Moos RH. Personal and contextual determinants of coping strategies. J Pers Soc Psychol. 1987;52(5):946-55.

29. Moos RH. Coping responses inventory: CRI adult form. Professional manual. Odessa: Psychological Assessment Resources, Inc; 1993

30. Moos R. Coping responses inventory: an update on research applications and validity. Odessa: Psychological Assessment Resources; 2004.

31. Maslach C, Jackson SE. Maslach burnout inventory. Palo Alto: Consulting Psychologists Press; 1986.

\section{Submit your next manuscript to BioMed Central and we will help you at every step:}

- We accept pre-submission inquiries

- Our selector tool helps you to find the most relevant journal

- We provide round the clock customer support

- Convenient online submission

- Thorough peer review

- Inclusion in PubMed and all major indexing services

- Maximum visibility for your research

Submit your manuscript at www.biomedcentral.com/submit
Biomed Central 